\title{
BMJ Open Adverse drug reactions to anticoagulants in Spain: analysis of the Spanish National Hospital Discharge Data (2010-2013)
}

P Carrasco-Garrido, ${ }^{1}$ V Hernández-Barrera, ${ }^{1} \mathrm{~J}$ Esteban-Hernández, ${ }^{1}$ I Jiménez-Trujillo, ${ }^{1}$ A Álvaro-Meca, ${ }^{1}$ A López de Andrés, ${ }^{1} \mathrm{~J}$ de Miguel Diez, ${ }^{2}$ $\mathrm{J}$ M Rodríguez Barrios, ${ }^{3} \mathrm{~J}$ A Muñoz Robles, ${ }^{4} \mathrm{R}$ Jiménez-García ${ }^{1}$

To cite: Carrasco-Garrido P, Hernández-Barrera V, Esteban-Hernández J, et al. Adverse drug reactions to anticoagulants in Spain: analysis of the Spanish National Hospital Discharge Data (2010-2013). BMJ Open 2017;7:e013224. doi:10.1136/bmjopen-2016013224

- Prepublication history for this paper is available online. To view these files please visit the journal online (http://dx.doi.org/10.1136/ bmjopen-2016-013224).

Received 27 June 2016 Revised 27 September 2016 Accepted 21 October 2016

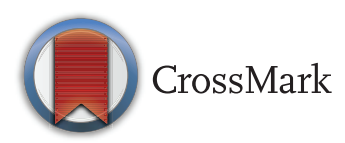

\footnotetext{
${ }^{1}$ Preventive Medicine and Public Health Teaching and Research Unit, Health Sciences Faculty Rey Juan Carlos University, Alcorcón, Spain

2Pneumology Department, Hospital General Universitario Gregorio Marañon, Madrid, Spain

${ }^{3}$ Daiichi Sankyo Europe $\mathrm{GmbH}$, Berlin, Germany

${ }^{4}$ Daiichi Sankyo España, S.A, Madrid, Spain
}

Correspondence to Dr P Carrasco-Garrido; pilar.carrasco@urjc.es

\section{ABSTRACT}

Objective: To describe and analyse hospitalisations for adverse drug reactions (ADRs) involving anticoagulants. We also analysed the progress of the reactions over time, the factors related with ADRs.

Design: A retrospective, descriptive, epidemiological study.

Setting: This study used the Spanish National Hospital Discharge Database (Conjunto Mínimo Básico de Datos, CMBD), over a 4-year period.

Participants: We selected CMBD data corresponding to hospital discharges with a diagnosis of ADRs to anticoagulants (International Classification of Diseases-Ninth Revision, Clinical Modification (ICD-9CM) code E934.2) in any diagnostic field during the study period.

Main outcome measures: We calculated the annual incidence of ADRs to anticoagulants according to sex and age groups. The median lengths of hospital stay and in-hospital mortality (IHM) were also estimated for each year studied. Bivariate analyses of the changes in variables according to year were based on Poisson regression. IHM was analysed using logistic regression models. The estimates were expressed as ORs and their $95 \% \mathrm{Cl}$.

Results: During the study period, 50042 patients were hospitalised because of ADRs to anticoagulants (6.38\% of all ADR-related admissions). The number of cases increased from 10415 in 2010 to 13891 in 2013. Cumulative incidence of ADRs to anticoagulants was significantly higher for men than women and in all age groups. An adjusted multivariate analysis revealed that IHM did not change significantly over time. We observed a statistically significant association between IHM and age, with the highest risk for the $\geq 85$ age group (OR 2.67; 95\% Cl 2.44 to 2.93).

Conclusions: The incidence of ADRs to anticoagulants in Spain increased from 2010 to 2013, and was significantly higher for men than women and in all age groups. Older patients were particularly susceptible to being hospitalised with an adverse reaction to an anticoagulant.

\section{Strengths and limitations of this study}

- The strength of our investigation lies in its large sample size, its 4-year follow-up period and its standardised methodology.

- The second strength is that it has previously been used to investigate adverse drug reaction (ADR)-related hospital admissions in Spain and elsewhere.

- A limitation of this study is that the possibility that ADR-related hospitalisations also include cases in which the ADR occurred during admission.

\section{INTRODUCTION}

Adverse drug reactions (ADRs) are a major health problem owing to their impact on morbidity and mortality. The WHO has defined an ADR as 'any response to a drug which is noxious, unintended and occurs at doses normally used for prophylaxis, diagnosis or therapy of disease, or for modification of physiological function. ${ }^{1}$ Investigators have performed numerous studies to estimate the incidence of ADRs and have found that between $1.3 \%$ and $11.1 \%$ of all hospital admissions are due to ADRs. ${ }^{2-7}$ The importance of ADRs was highlighted by the fact that since Lazarou et $a \ell^{\beta}$ concluded that the incidence of fatal ADRs in US hospitals was extremely high $(0.31 \%$ of all hospitalisations in the late 1990s), other authors have found that hospital mortality resulting from ADRs ranges from $4.3 \%$ to $10.2 \% .^{5} 9-12$

Research on ADRs also attempts to identify which drugs are most commonly associated with the onset of reactions. Anticoagulants are frequently involved in ADRs requiring hospitalisation. ${ }^{11-17}$ This circumstance is reflected in several studies, such as that 
carried out in the Netherlands by Ruiter et $a t^{2}$ among individuals aged $\geq 55$ years, which showed that almost $23 \%$ of hospital admissions for ADRs were associated with anticoagulants, and that carried out on elderly patients in France, showed that $25.8 \%$ of hospitalisations for ADRs involved anticoagulants. ${ }^{11}$ Anticoagulants have marked innate toxicity, and oral anticoagulants in particular require close monitoring to ensure safe use. The vitamin $\mathrm{K}$ antagonists (VKAs) like warfarin are highly effective in treating and preventing thrombosis, but despite its prolific use, these anticoagulants have several disadvantages. These include a narrow therapeutic index, delayed onset and offset of effect, multiple drug interactions, and requirements for monitoring and highquality dose management. ${ }^{13}$ In addition, anticoagulants are often used in elderly persons ${ }^{14-16}$ and patients with heart problems, ${ }^{17-19}$ who are more susceptible to ADRs.

The objectives of this study are to describe and analyse hospitalisations for ADRs involving anticoagulants based on data from a national hospital discharge database over a 4-year period. We also analyse the progress of the reactions over time, the factors associated with ADRs, and in-hospital outcomes such as in-hospital mortality (IHM) and length of hospital stay.

\section{METHODS}

Definition

According to Spanish legislation, ADRs are noxious and unintended response to drugs. They are considered serious when they are lethal or can be life threatening, are the cause of a defect or congenital malformation, can cause significant or lasting disability or can cause or prolong hospitalisation.

\section{Setting}

We performed a retrospective, descriptive, epidemiological study using the Spanish National Hospital Discharge Database (Conjunto Mínimo Básico de Datos, CMBD), which is managed by the Spanish Ministry of Health, Social Services and Equality. The database compiles all public and private hospital data, thus enabling it to cover more than $95 \%$ of hospital discharges. ${ }^{19}$ The CMBD includes patient variables (sex, date of birth), admission date, discharge date, up to 14 discharge diagnoses, and up to 20 procedures performed during the hospital stay. The characteristics of all hospital admissions are registered by medical doctors on the basis of hospital discharge letters and coded by professional coding clerks. The Spanish Ministry of Health, Social Services and Equality sets standards for recordkeeping and performs periodic audits. ${ }^{20}$ Data collected between 1 January 2010 and 31 December 2013 were analysed. Disease and procedure criteria were defined according to the International Classification of Diseases-Ninth Revision, Clinical Modification (ICD-9-CM), ${ }^{21}$ which is used in the Spanish CMBD.
We selected CMBD data corresponding to hospital discharges with a diagnosis of ADRs to anticoagulants (ICD-9-CM code E934.2 (coumarin, phenindione, heparin, prothrombin synthesis inhibitors and warfarin)) in any diagnostic field during the study period. Other adverse events (eg, accidents, suicides, accidental overdose and dosing errors) were excluded. The median length of hospital stay and IHM were also estimated for each year studied.

Clinical characteristics included information on overall comorbidity at the time of diagnosis, which was assessed using the Charlson comorbidity index (CCI). The index includes 17 categories of comorbid disease, the scores of which are added to obtain an overall score for each patient. ${ }^{22}$

\section{Data analysis}

A descriptive statistical analysis was performed. Depending on their type and distribution, variables were described using percentages, mean with SD and median with IQR. Bivariate analyses of the changes in variables according to year were based on Poisson regression (relative change for incidence by year of discharge), Pearson's $\chi^{2}$ test (percentages), analysis of variance (means), and the Kruskal-Wallis test (medians). Interactions have been checked according to sex. No sex interaction was found.

We calculated the annual age-specific incidence by dividing the number of cases per year per age group by the corresponding number of people in that population group using data from the National Institute of Statistics reported on 31 December each year. ${ }^{23}$ We also assessed the number of ADRs to anticoagulants among hospitalised patients and expressed this as a percentage of all hospital admissions in Spain between 2010 and 2013. In addition, we assessed the number of ADRs to anticoagulants among hospitalised patients with respect to the total number of prescriptions for this drug group in Spain between 2010 and 2013. Data on dispensed medical products were obtained from the National Health Prescription Register of the Spanish Ministry of Health, Social Services and Equality. ${ }^{24}$ Data from this database were selected at the pharmacological subgroup level B01A code (excluding B01AE and B01AF codes), according to the Anatomical Therapeutic Chemical (ATC) classification system. All data were grouped, thus preventing identification of individual patients.

In order to test the time trend for IHM, logistic regression analyses were performed with mortality as a binary outcome using year of discharge, sex, age and CCI as independent variables. The estimates were expressed as ORs and their $95 \%$ CI.

Statistical analyses were performed using Stata V.14.0 (Stata Corp LP, College Station, Texas, USA). Statistical significance was set at $\mathrm{p}<0.05$ (two-tailed).

\section{Ethical aspects}

Data confidentiality was maintained at all times according to Spanish legislation. Patient identifiers were deleted before the database was provided to the authors 
in order to maintain patient anonymity. It is not possible to identify patients at the individual level in this article or in the database. Given the anonymous and mandatory nature of the data set, it was not necessary to obtain informed consent.

\section{RESULTS}

During the 4-year study period, 50042 individuals were hospitalised with an ADR to an anticoagulant as their primary or secondary diagnosis $(6.38 \%$ of all ADR-related admissions $(50042 / 784635))$. Figure 1 shows the total number of hospitalisations associated with ADRs to anticoagulants during the study period, taking into account the corresponding number of people in that population group, all hospital admissions in Spain between 2010 and 2013, and total number of prescriptions dispensed during this period. Irrespective of the numerator used, an increase in the incidence of hospitalisations with ADRs to anticoagulants can be observed.

The principal characteristics of the study population are summarised in table 1 . Mean age was $79.4 \pm 9.5$ years, and most of the patients $(52.6 \%)$ were women. CCI increased from 1.61 to 1.74 during the study period. Patients hospitalised with an ADR to anticoagulants had high frequency of medical conditions such as atrial fibrillation (AF; $63.16 \%$ ), congestive heart failure $(40.39 \%)$, chronic obstructive pulmonary disease $(30.24 \%)$, diabetes and renal disease. The median length of stay fell from 8 (IQR=3) days in 2010 to $7(\mathrm{IQR}=2)$ days in 2013 $(\mathrm{p}=0.00)$. IHM varied little during the study period (from $10 \%$ in 2010 to $10.2 \%$ in 2013 ).

Table 2 shows the annual hospital discharge rates for patients with an ADR to anticoagulants by sex and age group. The cumulative incidence of discharges increased from 22.3 cases per 100000 inhabitants in 2010 to 29.8 cases per 100000 inhabitants in 2013 (ie, a $24.9 \%$ increase). Cumulative incidence was significantly higher for men than women and in all age groups, although the main increases were observed in the older age groups $(26.30 \%$ in patients aged $\geq 85$ years; $p<0.05)$. The most frequent primary diagnoses and procedures most commonly associated with ADRs according to IHM are summarised in table 3. It is noteworthy that $20.6 \%$ of patients who died during their hospitalisation had a primary diagnosis of cardiovascular disease (ICD-9 codes 428, 402.91, 428.1, 404.91, 415.19, 428.9, 410.71, 411.1 and 428.23$)$ and $16.8 \%$ had a primary diagnosis of bleeding (ICD-9 codes 729.92, 578.9, 578.1, 569.3, 431, 38.9, 599.71, 562.12, 599.7, 784.7, 786.3, 285.1 and 578), intracranial haemorrhage has been the most frequent diagnosis $(5.23 \%)$, followed by blood vessel puncture $(4.15 \%)$. The most frequent procedure administered during admission was blood transfusion (18.8\%).

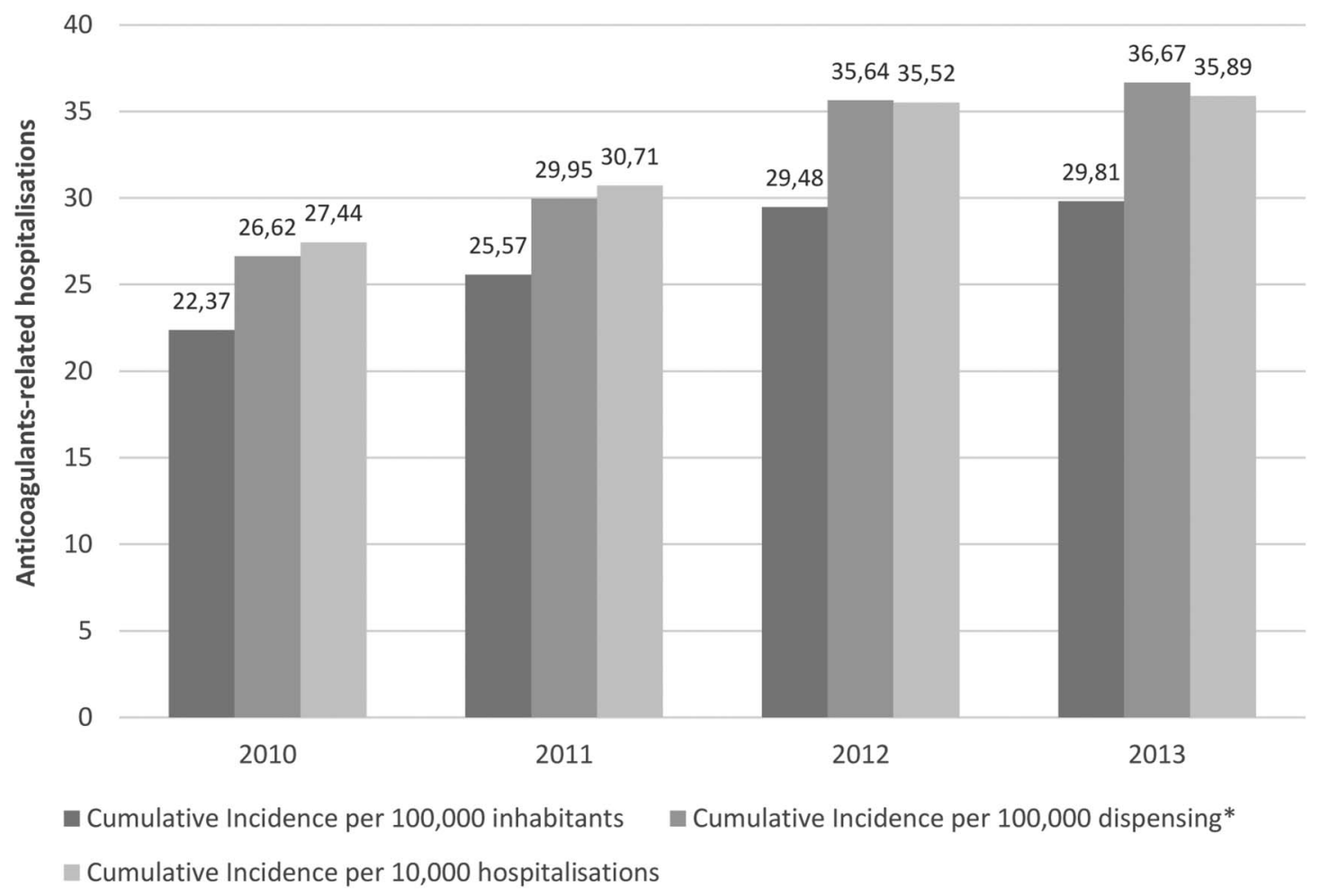

Figure 1 ADRs to anticoagulant in Spain during the period 2010-2013. National Hospital Discharge Database (CMBD). *Number of prescriptions dispensed BO1A ATC code (except B01AE and B01AF): 39118749 (year 2010); 39899992 (year 2011); 38674897 (year 2012) and 37877714 (year 2013). ADR, adverse drug reaction; ATC, Anatomical Therapeutic Chemical; CMBD, Conjunto Mínimo Básico de Datos. 
Table 1 Baseline characteristics of ADRs to anticoagulants anticoagulant in Spain during the period 2010-2013

\begin{tabular}{|c|c|c|c|c|c|c|}
\hline & $\begin{array}{l}2010 \\
N(\%)\end{array}$ & $\begin{array}{l}2011 \\
N(\%)\end{array}$ & $\begin{array}{l}2012 \\
\text { N (\%) }\end{array}$ & $\begin{array}{l}2013 \\
N(\%)\end{array}$ & $\begin{array}{l}\text { Total } \\
\mathrm{N}(\%)\end{array}$ & $p$ Value \\
\hline Female & 5509 (52.89) & $6264(52.41)$ & $7287(52.86)$ & 7304 (52.58) & 26364 (52.68) & 0.857 \\
\hline Age, mean (SD) & $78.92(9.6)$ & $79.24(9.56)$ & $79.66(9.48)$ & $79.81(9.51)$ & 79.45 (9.54) & $<0.0001$ \\
\hline $\begin{array}{l}\text { Charlson comorbidity index, } \\
\text { mean (SD) }\end{array}$ & $1.61(1.07)$ & $1.64(1.08)$ & $1.68(1.09)$ & 1.74 (1.09) & 1.67 (1.09) & $<0.0001$ \\
\hline Myocardial infarction & $547(5.25)$ & $610(5.1)$ & $649(4.71)$ & $580(4.18)$ & $2386(4.77)$ & $<0.0001$ \\
\hline Congestive heart failure & 3987 (38.28) & 4581 (38.33) & $5697(41.33)$ & $5949(42.83)$ & 20214 (40.39) & $<0.0001$ \\
\hline Peripheral vascular disease & $537(5.16)$ & $659(5.51)$ & $743(5.39)$ & $810(5.83)$ & 2749 (5.49) & 0.131 \\
\hline Cerebrovascular disease & $1225(11.76)$ & $1410(11.8)$ & $1546(11.22)$ & $1645(11.84)$ & $5826(11.64)$ & 0.332 \\
\hline Dementia & 478 (4.59) & $560(4.69)$ & $686(4.98)$ & 666 (4.79) & $2390(4.78)$ & 0.524 \\
\hline Chronic pulmonary disease & $3070(29.48)$ & $3562(29.81)$ & 4181 (30.33) & 4319 (31.09) & $15132(30.24)$ & 0.032 \\
\hline $\begin{array}{l}\text { Connective tissue disease- } \\
\text { rheumatic disease }\end{array}$ & $248(2.38)$ & $256(2.14)$ & 275 (1.99) & $329(2.37)$ & $1108(2.21)$ & 0.102 \\
\hline Peptic ulcer disease & $188(1.81)$ & $181(1.51)$ & $216(1.57)$ & $174(1.25)$ & 759 (1.52) & 0.006 \\
\hline Mild liver disease & 415 (3.98) & 444 (3.72) & $523(3.79)$ & $567(4.08)$ & 1949 (3.89) & 0.403 \\
\hline $\begin{array}{l}\text { Diabetes without chronic } \\
\text { complication }\end{array}$ & $2650(25.44)$ & 3104 (25.97) & $3512(25.48)$ & $3623(26.08)$ & $12889(25.76)$ & 0.541 \\
\hline $\begin{array}{l}\text { Diabetes with chronic } \\
\text { complication }\end{array}$ & $290(2.78)$ & 327 (2.74) & $423(3.07)$ & $450(3.24)$ & $1490(2.98)$ & 0.059 \\
\hline Hemiplegia or paraplegia & $111(1.07)$ & $150(1.26)$ & $187(1.36)$ & $199(1.43)$ & $647(1.29)$ & 0.075 \\
\hline Renal disease & $2194(21.07)$ & $2672(22.36)$ & $3290(23.87)$ & $3552(25.57)$ & $11708(23.4)$ & $<0.0001$ \\
\hline Cancer & $487(4.68)$ & $650(5.44)$ & 727 (5.27) & $718(5.17)$ & $2582(5.16)$ & 0.064 \\
\hline Moderate or severe liver disease & $94(0.9)$ & $115(0.96)$ & $140(1.02)$ & $143(1.03)$ & $492(0.98)$ & 0.752 \\
\hline Metastatic carcinoma & $260(2.5)$ & $316(2.64)$ & $333(2.42)$ & $365(2.63)$ & $1274(2.55)$ & 0.597 \\
\hline AIDS/HIV & $11(0.11)$ & $14(0.12)$ & $12(0.09)$ & $17(0.12)$ & $54(0.11)$ & 0.819 \\
\hline Atrial fibrillation & $6441(61.84)$ & 7450 (62.34) & 8792 (63.78) & $8924(64.24)$ & 31607 (63.16) & $<0.0001$ \\
\hline Thromboembolism & $281(2.7)$ & $283(2.37)$ & $325(2.36)$ & $335(2.41)$ & $1224(2.45)$ & 0.308 \\
\hline Hypertension & 4156 (39.9) & $4835(40.46)$ & 5618 (40.75) & $5452(39.25)$ & 20061 (40.09) & 0.059 \\
\hline Anaemia & 3147 (30.22) & $3513(29.4)$ & $4180(30.32)$ & 4107 (29.57) & $14947(29.87)$ & 0.279 \\
\hline Surgery & 689 (6.62) & $748(6.26)$ & $774(5.61)$ & $818(5.89)$ & $3029(6.05)$ & 0.007 \\
\hline Red cell transfusion & 2063 (19.81) & 2339 (19.57) & 2678 (19.43) & 2360 (16.99) & $9440(18.86)$ & $<0.0001$ \\
\hline In-hospital mortality & $1042(10)$ & 1205 (10.08) & $1491(10.82)$ & $1424(10.25)$ & $5162(10.32)$ & 0.134 \\
\hline LOSH, median (IQR) & $8(5-13)$ & $7(4-13)$ & $7(4-12)$ & $7(4-12)$ & $8(4-13)$ & $<0.0001$ \\
\hline
\end{tabular}

An adjusted multivariate analysis (table 4) revealed that IHM did not change significantly over time. We observed a statistically significant association between IHM and age, with the highest risk for the $\geq 85$ age group (OR 2.67; $95 \%$ CI 2.44 to 2.93).

A higher CCI was associated with a higher risk of death during admission (OR 1.21; $95 \%$ CI 1.18 to 1.25 ). Other factors associated with higher IHM were having a blood transfusion administered, whereas having AF (OR 0.88 ; $95 \%$ CI 0.83 to 0.94 ) as a diagnosis showed a protective effect.

\section{DISCUSSION}

Oral anticoagulants are often associated with ADRs requiring admission to hospital. ${ }^{15} 1725$ Using data from the CMBD, we found that between 2010 and 2013, a total of 50042 hospitalisations in Spain were with an ADR to anticoagulant drugs (ie, $6.38 \%$ of all hospitalisations with ADRs). This information is consistent with the $7.5 \%$ reported for anticoagulants in a study covering the period 2001-2006 to estimate the burden of ADR-related hospitalisations in Spain. ${ }^{9}$ The values we report are lower than those found in the 5-year study performed by Ruiter $e t a l^{2}$ in the Netherlands, in which 23\% of ADR-related hospital admissions in individuals aged $\geq 55$ years were associated with anticoagulants. Our results are also lower than the $18.3 \%$ frequency of adverse reactions to anticoagulants reported in a recent German study on the impact of ADR-related admissions to internal medicine departments, although the study period was shorter than ours. ${ }^{26}$ The results of our study show an increase in the incidence of ADR-related hospitalisations during the study period, irrespective of whether the numerator is the general population, the number of hospital admissions or the number of prescriptions of anticoagulants. All three options are suitable for a qualitative analysis to identify the age groups at greatest risk. In addition, the high proportion of elderly patients, with more frequent comorbidity and polypharmacy, is consistent with data from other studies. $^{714}$ 


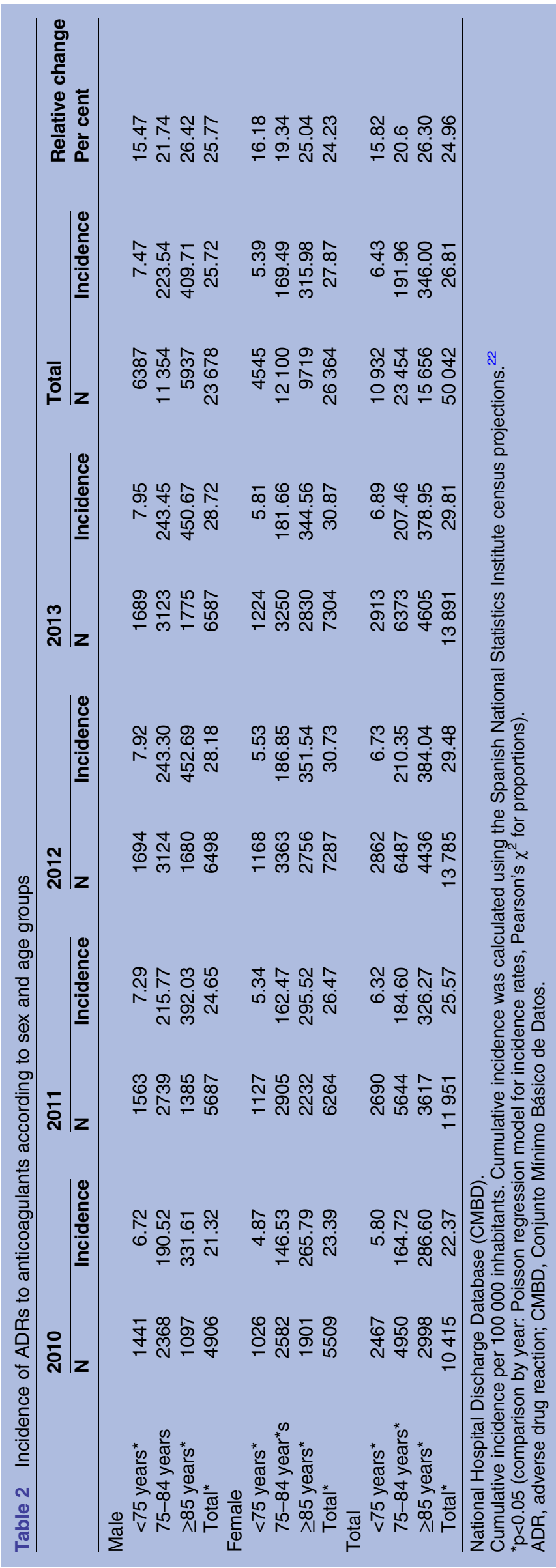

Female sex is a recognised risk factor for adverse reactions to specific groups of drugs. ${ }^{2} 72728$ If we focus on the safety profile of anticoagulant drugs, we find that the potential sex differences in the onset of adverse reactions have also been analysed in several meta-analyses, with varying results. ${ }^{29-31}$ However, in our study, sex as a risk factor behaved differently. During the 4-year study period, we observed an increase in the incidence of anticoagulant-related hospitalisations, which was greater in men than in women for all age groups. These data are consistent with those reported by Rodenburg et $a l^{32}$ whose objective was to identify possible differences in ADRs to cardiovascular drugs between men and women over a 6 -year period. The authors found that admissions for ADRs to anticoagulants and salicylates were more common in men (RR $0.94 ; 95 \%$ CI 0.90 to 0.98 ). In recent years, it has become clear that women and men differ in their response to anticoagulant drugs, as shown in the study by Blanco-Molina $e t a l^{33}$ in Spain, in which analysis of a sample of 47499 patients with venous thromboembolism showed that the outcome of therapy with anticoagulants could vary depending on the sex of the patient. Similarly, a recent study in primary care performed by Precioso Costa $e t a l^{34}$ to determine the degree of control and adherence to therapy in a sample of patients treated with acenocoumarol found that poor control of the international normalised ratio was more common among men $(2.77 \pm 0.11)$ than among women $(2.66 \pm 0.08$; $\mathrm{p}<0.05)$.

Our analysis of the CMBD registers showed that most patients hospitalised for ADRs to anticoagulants were elderly persons aged $79.45 \pm 9.54$ years with various clinical conditions such as congestive heart failure and $\mathrm{AF}$, which increase the vulnerability of this group to anticoagulant-induced ADRs. Our results show that the severity of the underlying disease, as expressed by the CCI (1.67 \pm 1.09$)$, was high in patients admitted to hospital with anticoagulant-induced reactions; this finding is consistent with those of the study of Alexopoulou $e t a l^{55}$ in Greece, where patients who had been hospitalised for ADRs had more comorbid conditions (CCI 1.7) than patients admitted for other reasons. Nevertheless, we must not forget that having multiple comorbidities is associated with polypharmacy, ${ }^{12}$ as described in a recent study performed in France by Olivier et $a l^{11}$ in patients aged $\geq 65$ years and in whom the number of drugs taken was a risk factor for ADR-associated hospitalisations (OR $1.18 ; 95 \%$ CI 1.08 to 1.29 ).

Oral anticoagulants are the most effective therapy for the prevention of ischaemic stroke and systemic embolism related to AF. During the previous decade, the number of patients who received treatment with oral anticoagulants has increased, mainly owing to the higher number of elderly patients with $\mathrm{AF}^{36}{ }^{37}$ for whom this therapy is indicated in order to prevent cerebrovascular accidents. ${ }^{38}$ Analysis of primary diagnoses associated with ADRs to anticoagulants among 
Table 3 Most frequent primary diagnoses and procedures among ADRs to anticoagulants according to in-hospital mortality in Spain, 2010-2013

\begin{tabular}{|c|c|c|c|c|c|c|}
\hline \multirow{3}{*}{$\begin{array}{l}\text { Primary diagnosis (ICD-9 codes) } \\
\text { Cardiovascular disease }(428,402.91,428.1, \\
404.91,415.19,428.9,410.71,411.1,428.23)\end{array}$} & \multicolumn{6}{|c|}{ Outcome } \\
\hline & \multicolumn{2}{|c|}{$\begin{array}{l}\text { Survival to hospital } \\
\text { discharge (N, \%) }\end{array}$} & \multicolumn{2}{|c|}{$\begin{array}{l}\text { Died during } \\
\text { admission }(\mathrm{N}, \%)\end{array}$} & \multicolumn{2}{|c|}{ Total (N, \%) } \\
\hline & 8196 & 18.26 & 1068 & 20.69 & 9264 & 18.51 \\
\hline $\begin{array}{l}\text { Bleeding }(729.92,578.9,578.1,569.3,431,38.9 \text {, } \\
599.71,562.12,599.7,784.7,786.3,285.1,578)\end{array}$ & 6530 & 14.55 & 870 & 16.85 & 7400 & 14.79 \\
\hline $\begin{array}{l}\text { Respiratory disease }(519.8,491.21,518.81,466 \text {, } \\
518.84,491.22,494.1,493.92)\end{array}$ & 5764 & 12.84 & 490 & 9.49 & 6254 & 12.5 \\
\hline Pneumonias $(486,507,481)$ & 3257 & 7.26 & 425 & 8.23 & 3682 & 7.36 \\
\hline Renal disease $(599,584.9)$ & 1868 & 4.16 & 237 & 4.59 & 2105 & 4.21 \\
\hline Anaemia $(280,280.9,285.9)$ & 942 & 2.1 & 41 & 0.79 & 983 & 1.96 \\
\hline Atrial fibrillation (427.31) & 800 & 1.78 & 37 & 0.72 & 837 & 1.67 \\
\hline \multicolumn{7}{|l|}{ Procedures } \\
\hline Surgery & 2657 & 5.92 & 372 & 7.21 & 3029 & 6.05 \\
\hline Red cell transfusion & 8416 & 18.75 & 1024 & 19.84 & 9440 & 18.86 \\
\hline
\end{tabular}

National Hospital Discharge Database (CMBD).

ADR, adverse drug reaction; CMBD, Conjunto Mínimo Básico de Datos; ICD-9, International Classification of Diseases-Ninth Revision.

Table 4 Multivariate analysis of the factors associated with IHM for all participants with ADRs to anticoagulants in Spain, from 2010 to 2013

\begin{tabular}{ll}
\hline & OR (CI 95\%) \\
\hline $\begin{array}{l}\text { Age groups (years) } \\
<75\end{array}$ & 1 \\
$75-84$ & $1.65(1.50$ to 1.80$)$ \\
$\geq 85$ & $2.67(2.44$ to 2.93$)$ \\
Sex & \\
$\quad$ Male & 1 \\
Female & $0.99(0.93$ to 1.05$)$ \\
Charlson comorbidity index & $1.21(1.18$ to 1.25$)$ \\
Red cell transfusion & \\
No & 1 \\
Yes & $1.09(1.01$ to 1.17$)$ \\
Atrial fibrillation & \\
No & 1 \\
Yes & $0.88(0.83$ to 0.94$)$ \\
Years & \\
2013 & 1 \\
2012 & $1.08(0.99$ to 1.06$)$ \\
2011 & $1.01(0.93$ to 1.10$)$ \\
2010 & $1.02(0.94$ to 1.11$)$ \\
\hline
\end{tabular}

National Hospital Discharge Database (CMBD).

Calculated using logistic regression models: OR. The logistic regression multivariate models were built using 'death (yes/no)' as dependent variables.

ADR, adverse drug reaction; CMBD, Conjunto Mínimo Básico de Datos; IHM, in-hospital mortality.

hospitalised patients reveals that the primary diagnosis was cardiovascular disease in $18.5 \%$ of cases and $\mathrm{AF}$ in $1.67 \%$ of cases, thus potentially explaining why these patients were receiving treatment with anticoagulants. Other diagnoses, such as bleeding (14.79\%) and blood transfusion $(18.86 \%)$ could indicate the reason why patients were hospitalised or what happened during hospitalisation. Finally, although not associated with anticoagulant drugs, primary diagnoses such as renal insufficiency $(4.21 \%)$ could be considered a risk factor if the patient's consumption of anticoagulants is high.

With respect to bleeding as the main diagnosis, our results are consistent with those of studies that associate this diagnosis as the main adverse reaction to anticoagulants. Piazza et $a l^{15}$ performed a 5-year retrospective study to determine the clinical characteristics, types and outcomes of adverse events associated with anticoagulant drugs and found that $25 \%$ of adverse reactions comprised bleeding events and that $17 \%$ required transfusion of at least one unit of packed red blood cells. However, it is important to remember that the predictors of bleeding in patients undergoing treatment with anticoagulants are mainly clinical factors that include uncontrolled hypertension, a history of myocardial infarction or ischaemic heart disease, cerebrovascular disease, anaemia or a history of bleeding, and concomitant use of other drugs such as antiplatelet agents. ${ }^{39}$

Patients admitted for adverse reactions to anticoagulants often die, usually because of the profile of patients taking these drugs (eg, old age, comorbidity and polypharmacy). ${ }^{40}$ We found that the IHM associated with adverse reactions to anticoagulants remained constant throughout the study period, with values close to $10 \%$, which were higher than the $6.9 \%$ reported by Heng et $a l^{25}$ based on the data from the French Database Programme de Médicalisation des Systèmes d'Information (PMSI), including patients aged $>75$ years.

In contrast with results from other studies, where fatal ADRs seem mainly to affect women, ${ }^{12}$ IHM did not seem to be affected by sex in our study.

Our multivariate analysis showed that individuals aged $\geq 85$ years who were admitted to hospital with adverse reactions to anticoagulants are twice as likely to die as 
those aged <75 years (OR 2.67; 95\% CI 2.44 to 2.93 ). Similarly, the CCI acts as a predictor of IHM in this age group, since comorbidity worsens the patient's clinical status in the case of an adverse reaction to anticoagulants. In this context, it is noteworthy that $\mathrm{AF}$, the most common significant cardiac arrhythmia, is associated with substantial morbidity from stroke and thromboembolism. According to data from the OFRECE study, which analysed the prevalence of $\mathrm{AF}$ in Spain, the prevalence of $\mathrm{AF}$ in patients aged $>80$ years is high $(17.7 \%) \cdot{ }^{37} \mathrm{AF}$ is also associated with increased mortality, ${ }^{41}$ although our data analysis revealed that a diagnosis of $\mathrm{AF}$ is not a risk factor for IHM in patients admitted for adverse reactions to anticoagulants (OR 0.88 ; 95\% CI 0.83 to 0.94 ). We have analysed three groups: patients without $\mathrm{AF}$, patients with $\mathrm{AF}$ as comorbidity and patients with $\mathrm{AF}$ as the primary diagnosis. It can be observed that IHM values are similar between patients without $\mathrm{AF}$ and patients presenting $\mathrm{AF}$ as a comorbidity $(10.5 \%$ vs $10.4 \%)$. Patients with $\mathrm{AF}$ as a primary diagnosis have much lower IHM ( $4.4 \%$ vs $10 \%)$ Patients with $\mathrm{AF}$ as the first diagnosis are more frequently women $(65.7 \%$ vs $47.9 \%$ and $55.2 \%$ among those without $\mathrm{AF}$ and with $\mathrm{AF}$ as a comorbidity, respectively), with a mean age between the other two group (78.7 vs 76.8 years among those without $\mathrm{AF}$ and 81.1 years among those with $\mathrm{AF}$ as a comorbid condition) and with a mean Charlson index lower than the other groups two groups (1.5 vs 1.63 and 1.7 ).

This finding could be associated with the type of treatment of the disease in this patient group. VKA have long been the only available oral anticoagulant for prevention of the thromboembolic complications of AF. These drugs are clearly efficacious, with a relative reduction in the risk of ischaemic stroke in elderly patients. However, the clinical challenge of these drugs is to reach an optimal degree of protection under strict supervision owing to their narrow therapeutic margin, interactions with other drugs and the need for strict control of the degree of anticoagulation. Many patients on treatment with VKA spend time outside of the therapeutic range. Some recently published studies in Spain stress on the high percentage of patients who are not well controlled with VKAs. These values range from $41.5 \%$ to $43.7 \%$, according to the results of the CALIFA study, ${ }^{42}$ and the ANFAGAL study ${ }^{43}$ the prevalence of poorly controlled VKA anticoagulation in Spain in patients with nonvalvular $\mathrm{AF}$.

Newly developed anticoagulant agents, such as the direct thrombin inhibitor dabigatran etexilate and the direct factor $\mathrm{X}$ inhibitors rivaroxaban and apixaban and edoxaban were recently shown to have a favourable riskbenefit ratio under various clinical conditions where anticoagulants are indicated, as is the case with $\mathrm{AF}^{44}$ The meta-analysis conducted by Ruff $e t a l^{45}$ to assess the relative benefit of new oral anticoagulants in randomised trials in patients with $\mathrm{AF}$, showed that the new oral anticoagulants also significantly reduce all-cause mortality $(0.90,0.85$ to $0.95 ; \mathrm{p}=0.0003)$.

\section{Strengths and limitations}

Our study has both strengths and limitations. The main strength lies in the large sample size and standardised methodology, which was maintained throughout the study period and has previously been used to investigate ADR-related hospital admissions in Spain and elsewhere. $^{9} 16{ }^{26}$ We believe that the length of the study period and the exhaustive data provided by the CMBD provide sufficient internal validity, which, in quantitative terms, is seen in the constant frequency of episodes detected every year and, in qualitative terms, in the identification of the age groups at the greatest risk.

Nevertheless, our study is subject to limitations. Given that our findings are based on the diagnosis at discharge, the cumulative incidence of ADRs to anticoagulants among hospitalised patients is probably substantially underestimated. Another limitation is the possibility that ADR-related hospitalisations also include cases in which the ADR occurred during admission, although in our opinion, the possibility that an adverse reaction to an anticoagulant during admission is coded as the main diagnosis seems very low. Furthermore, as a consequence of the study design, we were not able to verify whether the patient was already taking an anticoagulant or whether the reaction resulted from taking an anticoagulant during admission. The Spanish National Hospital Discharge Database (CMBD), includes no data regarding patient treatments or drug consumption. Spanish CMBD does not include data regarding the time of start of treatment with anticoagulants before the adverse reaction appeared. Consequently, it has not been possible for us to include any data in the polymedication analysis that would allow us to assess drug interactions with anticoagulants. In addition, we were unable to specify which specific anticoagulant or type of anticoagulant the patient took. We were unable to identify in detail the specific pharmacological classes involved in ADRs to anticoagulants among hospitalised patients.

\section{CONCLUSIONS}

In conclusion, during the study period, 50042 individuals were hospitalised in Spain for adverse reactions to anticoagulants.

Cumulative incidence increased during this time and was significantly higher for men than women and in all age groups. Older patients were particularly susceptible to being hospitalised with an adverse reaction to an anticoagulant. Our results strongly suggest that individuals $>75$ years of age with a high CCI had a higher risk of death during admission.

Oral anticoagulant therapy is complex due to the need for control and the haemorrhagic risk the therapy entails The use of anticoagulants requires custom management and proper selection of treatments, since many of these patients have multiple comorbidities and polypharmacy and some anticoagulants have a high percentage of drug interactions. 
Acknowledgements The authors wish to thank the Spanish Ministry of Health, Social Services and Equality, for providing data.

Contributors All authors contributed to the conception and design of the study. PC-G and RJ-G originated and designed the study and coordinated the writing of the article. $\mathrm{VH}-\mathrm{B}$ contributed to the analysis of the data and to the drafting of the paper. JE-H, IJ-T, AA-M, ALdA, JdMD, JMRB and JAMR contributed to the interpretation of the results and to the drafting of the paper. All authors had full access to all the data in the study and take responsibility for the integrity of the data and the accuracy of the data analysis. All authors have seen and approved the final version. PC-G is the guarantor.

Funding This study forms part of research funded by the Daiichi Sankyo España, S.A grant no: 2015/00200/001-A295.

\section{Competing interests None declared.}

Ethics approval The study protocol was approved by the Ethics Committee of Universidad Rey Juan Carlos.

Provenance and peer review Not commissioned; externally peer reviewed.

Data sharing statement No additional data are available.

Open Access This is an Open Access article distributed in accordance with the Creative Commons Attribution Non Commercial (CC BY-NC 4.0) license, which permits others to distribute, remix, adapt, build upon this work noncommercially, and license their derivative works on different terms, provided the original work is properly cited and the use is non-commercial. See: http:// creativecommons.org/licenses/by-nc/4.0/

\section{REFERENCES}

1. WHO. Collaborating center for international drug monitoring. International monitoring of adverse reaction to drug: adverse reaction terminology. DEM/NC/81.30; 31. XXI; 1980. http://www.who.int/ medicines/areas/quality_safety/safety_efficacy/National_PV_ Centres Map/en.

2. Ruiter R, Visser LE, Rodenburg EM, et al. Adverse drug reactionrelated hospitalizations in persons aged 55 years and over: a population-based study in the Netherlands. Drugs Aging 2012;29:225-32.

3. Bénard-Laribière A, Miremont-Salamé G, Pérault-Pochat MC, et al., EMIR Study Group on behalf of the French network of pharmacovigilance centres. Incidence of hospital admissions due to adverse drug reactions in France: the EMIR study. Fundam Clin Pharmacol 2015;29:106-11.

4. Pedrós C, Quintana B, Rebolledo M, et al. Prevalence, risk factors and main features of adverse drug reactions leading to hospital admission. Eur J Clin Pharmacol 2014;70:361-7.

5. Wu TY, Jen MH, Bottle A, et al. Ten-year trends in hospital admissions for adverse drug reactions in England 1999-2009. J R Soc Med 2010;103:239-50.

6. Ahern F, Sahm LJ, Lynch D, et al. Determining the frequency and preventability of adverse drug reaction-related admissions to an Irish University Hospital: a cross-sectional study. Emerg Med J 2014;31:24-9.

7. Conforti A, Costantini D, Zanetti F, et al. Adverse drug reactions in older patients: an Italian observational prospective hospital study. Drug Healthc Patient Saf 2012;4:75-80.

8. Lazarou J, Pomeranz BH, Corey PN. Incidence of adverse drug reactions in hospitalized patients: a meta-analysis of prospective studies. JAMA 1998;279:1200-5.

9. Carrasco-Garrido P, de Andrés LA, Barrera VH, et al. Trends of adverse drug reactions related-hospitalizations in Spain (20012006). BMC Health Serv Res 2010;10:287.

10. Bouvy JC, De Bruin ML, Koopmanschap MA. Epidemiology of adverse drug reactions in Europe: a review of recent observational studies. Drug Saf 2015;38:437-53.

11. Olivier $\mathrm{P}$, Bertrand L, Tubery $\mathrm{M}$, et al. Hospitalizations because of adverse drug reactions in elderly patients admitted through the emergency department: a prospective survey. Drugs Aging 2009;26:475-82.

12. Pedrós $\mathrm{C}$, Formiga $\mathrm{F}$, Corbella $\mathrm{X}$, et al. Adverse drug reactions leading to urgent hospital admission in an elderly population: prevalence and main features. Eur J Clin Pharmacol 2016;72:219-26.
13. Shameem R, Ansell J. Disadvantages of VKA and requirements for novel anticoagulants. Best Pract Res Clin Haematol 2013;26:103-14.

14. Classen DC, Jaser L, Budnitz DS. Adverse drug events among hospitalized Medicare patients: epidemiology and national estimates from a new approach to surveillance. Jt Comm J Qual Patient Saf 2010;36:12-21.

15. Piazza G, Nguyen TN, Cios D, et al. Anticoagulation-associated adverse drug events. Am J Med 2011;124:1136-42.

16. Hartholt $\mathrm{KA}$, van der Velde $\mathrm{N}$, Looman $\mathrm{CW}$, et al. Adverse drug reactions related hospital admissions in persons aged 60 years and over, the Netherlands, 1981-2007: less rapid increase, different drugs. PLOS ONE 2010;5:e13977.

17. Fanikos J, Cina JL, Baroletti S, et al. Adverse drug events in hospitalized cardiac patients. Am J Cardiol 2007;100:1465-9.

18. Saheb Sharif-Askari N, Syed Sulaiman SA, Saheb Sharif-Askari F, et al. Adverse drug reaction-related hospitalisations among patients with heart failure at two hospitals in the United Arab Emirates. Int J Clin Pharm 2015;37:105-12.

19. Ministerio de Sanidad Servicios Sociales e Igualdad. Real Decreto $577 / 2013$, de 26 de julio, por el que se regula la farmacovigilancia de medicamentos de uso humano. http://www.boe.es/boe/dias/2013/ 07/27/pdfs/BOE-A-2013-8191.pdf (accessed 23 May 2016).

20. Instituto Nacional de Gestión Sanitaria, Ministerio de Sanidad, Servicios Sociales e Igualdad: Conjunto Mínimo Básico de Datos, Hospitales del INSALUD. http://www.ingesa.msc.es/estadEstudios/ documPublica/CMBD-2001.htm (accessed 23 May 2016).

21. International Classification of Diseases. 9th Revision, Clinical Modification (ICD-9-CM). Michigan: Commission on Professional and Hospital Activities, 1978.

22. Deyo RA, Cherkin DC, Ciol MA. Adapting a clinical comorbidity index for use with ICD-9-CM administrative databases. J Clin Epidemiol 1992;45:613-19.

23. Instituto Nacional de Estadística (INE). Population estimates. www. ine.es Date last updated: 20 May 2016 (accessed: 22 May 2016).

24. Prescription file National Health System. Dirección General de Cartera Básica de Servicios del Sistema Nacional de Salud y Farmacia. http://www.msssi.gob.es/organizacion/ministerio/ organizacion/sgralsanidad/dgcbssnsyfF.htm (accessed 22 May 2016).

25. Heng C, Rybarczyk-Vigouret MC, Michel B. Anticoagulant-related hospital admissions: serious adverse reactions identified through hospital databases. Pharmacoepidemiol Drug Saf 2015;24:144-51.

26. Rottenkolber D, Schmiedl S, Rottenkolber M, et al., Net of Regional Pharmacovigilance Centers. Adverse drug reactions in Germany: direct costs of internal medicine hospitalizations Pharmacoepidemiol Drug Saf 2011:20:626-34.

27. Zopf $Y$, Rabe $C$, Neubert $A$, et al. Women encounter ADRs more often than do men. Eur J Clin Pharmacol 2008;64:999-1004.

28. Miguel A, Bernardo Marques A, Freitas A, et al. Detection of adverse drug reactions using hospital databases-a nationwide study in Portugal. Pharmacoepidemiol Drug Saf 2013;22:907-13.

29. Lapner S, Cohen N, Kearon C. Influence of sex on risk of bleeding in anticoagulated patients: a systematic review and meta-analysis. $J$ Thromb Haemost 2014;12:595-605.

30. Dentali F, Sironi AP, Gianni M, et al. Gender difference in efficacy and safety of nonvitamin $\mathrm{K}$ antagonist oral anticoagulants in patients with nonvalvular atrial fibrillation or venous thromboembolism: a systematic review and a meta-analysis of the literature. Semin Thromb Hemost 2015;41:774-87.

31. Pancholy SB, Sharma PS, Pancholy DS, et al. Meta-analysis of gender differences in residual stroke risk and major bleeding in patients with nonvalvular atrial fibrillation treated with oral anticoagulants. Am J Cardiol 2014;113:485-90.

32. Rodenburg EM, Stricker BH, Visser LE. Sex differences in cardiovascular drug-induced adverse reactions causing hospital admissions. Br J Clin Pharmacol 2012;74:1045-52.

33. Blanco-Molina A, Enea I, Gadelha T, et al. Sex differences in patients receiving anticoagulant therapy for venous thromboembolism. Medicine (Baltimore) 2014;93:309-17.

34. Precioso Costa FJ, Larré Muñoz MJ, Navarro Ros FM, et al. Level of control and treatment adherence of anticoagulation with acenocoumarol in Primary Care. Semergen 2016;42:363-9.

35. Alexopoulou A, Dourakis SP, Mantzoukis D, et al. Adverse drug reactions as a cause of hospital admissions: a 6-month experience in a single center in Greece. Eur $J$ Intern Med 2008;19:505-10.

36. Piccini JP, Hammill BG, Sinner MF, et al. Incidence and prevalence of atrial fibrillation and associated mortality among Medicare beneficiaries,1993-2007. Circ Cardiovasc Qual Outcomes 2012;5:85-93. 
37. Gómez-Doblas JJ, Muñiz J, Martin JJ, et al., OFRECE study collaborators. Prevalence of atrial fibrillation in Spain. OFRECE study results. Rev Esp Cardiol (Engl Ed) 2014;67:259-69.

38. Lip GY, Laroche C, Dan GA, et al. A prospective survey in European Society of Cardiology member countries of atrial fibrillation management: baseline results of EURObservational Research Programme Atrial Fibrillation (EORP-AF) Pilot General Registry. Europace 2014;16:941.

39. Hughes M, Lip GY. Risk factors for anticoagulation-related bleeding complications in patients with atrial fibrillation: a systematic review. QJM 2007;100:599-607.

40. Lapatto-Reiniluoto O, Patinen L, Niemi M, et al. Drug-related inadvertent deaths in a university hospital-a declining trend. Basic Clin Pharmacol Toxicol 2015;117:421-6.

41. Guize L, Thomas F, Bean K, et al. Atrial fibrillation: prevalence, risk factors and mortality in a large French population with 15 years of follow-up. Bull Acad Natl Med 2007;191:791-805.

42. Anguita Sánchez M, Bertomeu Martínez V, Cequier Fillat Á, CALIFA study researchers. Quality of vitamin K antagonist anticoagulation in
Spain: prevalence of poor control and associated factors. Rev Esp Cardiol (Engl Ed) 2015;68:761-8.

43. Cinza-Sanjurjo S, Rey-Aldana D, Gestal-Pereira E, et al., Investigators of the ANFAGAL (Anticoagulación en pacientes con Fibrilación Auricular en el ámbito de atención primaria de GALicia) study. Assessment of degree of anticoagulation control in patients with atrial fibrillation in primary health care in Galicia, Spain: ANFAGAL study. Rev Esp Cardiol (Engl Ed) 2015;68:753-60.

44. Criterios y recomendaciones generales para el uso de nuevos anticoagulantes orales (NACO) en la prevención del ictus y la embolia sistémica en pacientes con fibrilación auricular no valvular. Informe de posicionamiento terapéutico/V4/23122013. http:// www.aemps.gob.es/medicamentosUsoHumano/informesPublicos/ docs/criterios-anticoagulantes-orales.pdf (accessed 22 May 2016).

45. Ruff CT, Giugliano RP, Braunwald E, et al. Comparison of the efficacy and safety of new oral anticoagulants with warfarin in patients with atrial fibrillation: a meta-analysis of randomised trials. Lancet 2014;383:955-62. 